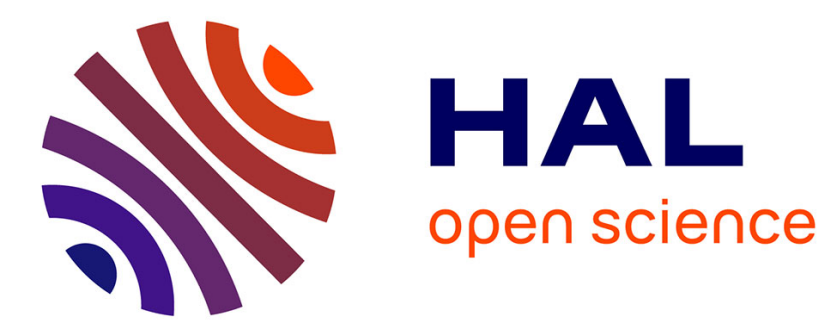

\title{
Powder/die friction in the spark plasma sintering process: Modelling and experimental identification
}

\author{
Charles Manière, Lise Durand, Claude Estournès
}

\section{To cite this version:}

Charles Manière, Lise Durand, Claude Estournès. Powder/die friction in the spark plasma sintering process: Modelling and experimental identification. Scripta Materialia, 2016, vol. 116, pp. 139-142. 10.1016/j.scriptamat.2016.01.040 . hal-01486908

\section{HAL Id: hal-01486908 \\ https://hal.science/hal-01486908}

Submitted on 10 Mar 2017

HAL is a multi-disciplinary open access archive for the deposit and dissemination of scientific research documents, whether they are published or not. The documents may come from teaching and research institutions in France or abroad, or from public or private research centers.
L'archive ouverte pluridisciplinaire HAL, est destinée au dépôt et à la diffusion de documents scientifiques de niveau recherche, publiés ou non, émanant des établissements d'enseignement et de recherche français ou étrangers, des laboratoires publics ou privés. 


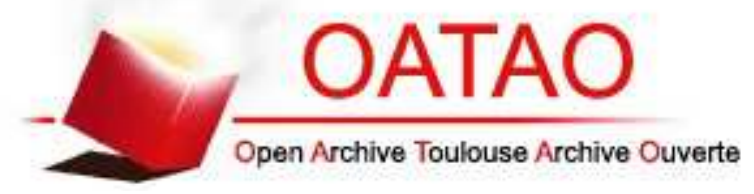

\section{Open Archive TOULOUSE Archive Ouverte (OATAO)}

OATAO is an open access repository that collects the work of Toulouse researchers and makes it freely available over the web where possible.

This is an author-deposited version published in : http://oatao.univ-toulouse.fr/ Eprints ID : 16740

To link to this article : DOI:10.1016/j.scriptamat.2016.01.040

URL : http://dx.doi.org/10.1016/j.scriptamat.2016.01.040

To cite this version : Manière, Charles and Durand, Lise and Estournès, Claude Powder/die friction in the spark plasma sintering process: Modelling and experimental identification. (2016) Scripta Materialia, vol. 116. pp. 139-142. ISSN 1359-6462

Any correspondence concerning this service should be sent to the repository administrator: staff-oatao@ listes-diff.inp-toulouse.fr 


\title{
Powder/die friction in the spark plasma sintering process: Modelling and experimental identification
}

\author{
Charles Manière ${ }^{\mathrm{a}, \mathrm{b}, \mathrm{c}}$, Lise Durand ${ }^{\mathrm{b}}$, Claude Estournès ${ }^{\mathrm{a}, \mathrm{c}, *}$ \\ a Université de Toulouse, Institut Carnot CIRIMAT, UMR 5085 CNRS-Université Toulouse III Paul-Sabatier-INPT, 118 route de Narbonne, 31062 Toulouse Cedex 9, France \\ b CEMES, CNRS UPR 8011, Université de Toulouse, 29 rue Jeanne Marvig, 31055 Toulouse, France \\ c CNRS, Institut Carnot CIRIMAT, 118 route de Narbonne, 31602 Toulouse Cedex 9, France
}

Keywords:

Spark plasma sintering

Creep

Friction

Finite element method

\begin{abstract}
A B S T R A C T
The powder/die friction phenomenon is known to generate densification inhomogeneities in the spark plasma sintered sample. The measurement of a powder/solid friction coefficient at high temperature is very difficult if not impossible by classical means. Then, an experimental/simulation method of identification of the friction coefficient based on the sample displacement field is introduced. This reveals that the friction of contact type powder/wall is low and about 0.1 and the friction type powder/graphite-foil/wall is close to zero. The relative density inhomogeneities are limited to a maximum difference of $3 \%$.
\end{abstract}

Spark plasma sintering (SPS) also known as Field-Assisted Sintering is a breakthrough technique in the field of powder consolidation technology [1-3]. This manufacturing approach involves the combination of external pressure and an electric pulsed current applied simultaneously to the powder (Fig.1). The process presents many benefits such as a strong reduction of the sintering temperature and/or time, minimizing granular growth and allowing nanostructured materials [4-7] to be sintered. The sintering of a wide range of materials (ceramics, metals and polymers) takes only a few minutes with the SPS technique compared to several hours or days with other techniques like Hot Pressing (HP) or free sintering.

However, the SPS tools itself remain a black box for which only the surface die temperature and the external applied pressure can be directly controlled. Most of the time, the sintering of complex shaped parts requires a better control and understanding of the thermal and pressure gradients present in the sample during the process. In order to predict the internal thermal gradients, Joule heating models of the SPS process are used. Several authors like [8-14] have emphasized the strong potential effect of the electric and thermal contacts present in every inner interface of the device. The die/sample temperature difference is generally quite high, ranging from some tens to hundreds Kelvin mainly due to contact resistances. The presence of hot spots at the edges of samples was experimentally reported in the PhD work of A. Pavia [15] and can be the object of strong local inhomogeneities in microstructure. In die configurations with non-common geometry, the thermal gradient can

\footnotetext{
* Corresponding author.

E-mail address: estournes@chimie.ups-tlse.fr (C. Estournès).
}

be exacerbated. Using such configurations, Functionally Graded Materials (FGM) [16-18] are elaborated with microstructural gradients.

Apart from the thermal gradients, microstructural differences may appear because of the presence of pressure inhomogeneities. A lot of experimental and theoretical studies [19-22] have shown the importance of height differences in the parts that cause high porosity gradients in complex shaped samples. To solve this problem of porosity gradients, sintering simulations are then performed. The sintering simulations can be used to predict the densification field at every stage of a sintering cycle. The main interest of these simulations is to verify the validity of the tooling configurations for the sintering of complex shaped parts without having recourse to expensive experimental "trial and error" adjustment testing. Powder compaction modelling in processes like SPS or HP is most often built on porous creep behaviour laws. The Abouaf [23], Olevsky [24,25] or Camclay [26] sintering models are the most widely cited in the literature. In order to describe either the thermal or mechanical aspect of the SPS process, fully coupled electro-thermal-mechanical-microstructural simulations can then be used to model the relative density/thermal/grain size gradients in a more relevant way.

Complex shapes are not the only source of pressure inhomogeneities. Even in simple shapes such as a cylindrical sample, pressure inhomogeneities can occur because of the powder/mould friction that creates a shear stress on the sliding wall. This effect and the related microstructural changes were studied by P. Mondalek [27]. In classical models, the friction is determined using the Coulomb law (1)

$\tau=\mu \tau_{n}$ 


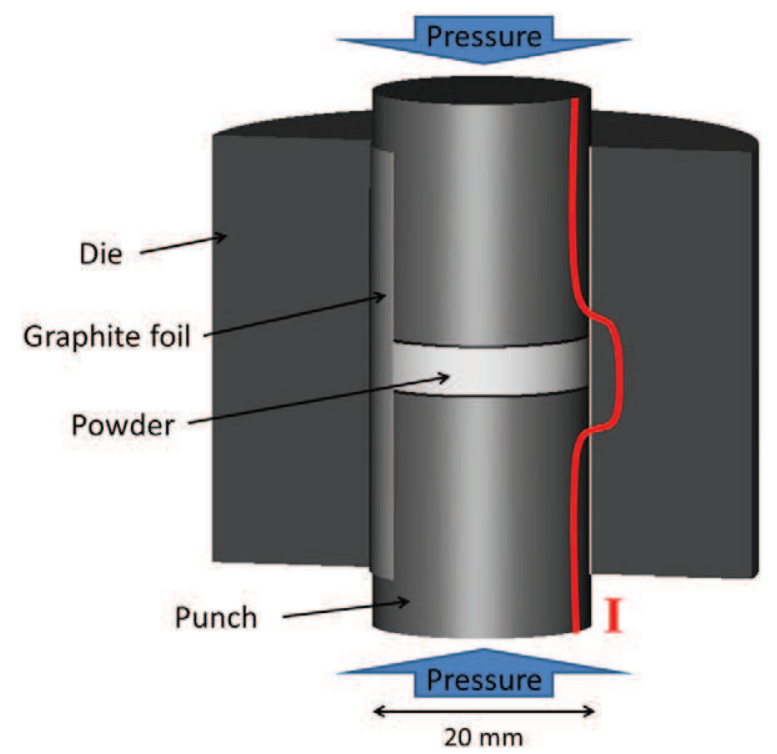

Fig. 1. Scheme of the spark plasma sintering process (I is the pulsed current).

where the tangential stress $\tau$ is a defined function of the friction coefficient $\mu$ (in displacement regime) and the normal pressure $\tau_{n}$.

For viscoplastic materials, a Norton-Hoff friction law (2) can also be used.

$\tau=-\mu K\left|\boldsymbol{V}_{g}\right|^{p-1} \boldsymbol{V}_{g}$

This Norton-Hoff creep (3) based friction law is a function of the material consistency $K(3)$, the sliding relative velocity $\boldsymbol{V}_{\boldsymbol{g}}$ and a constant $p$ that can be assimilated to the power law creep strain rate sensitivity $m$.

$\sigma_{\mathrm{eq}}=K \dot{\varepsilon}_{\mathrm{eq}}^{m}$.

The viscous friction law is particularly useful to start gradually with the increase of the relative velocity. Indeed, in displacement regime, the Coulomb law starts directly by the nominal shear stress, and this may create divergences leading to computing problems. In her work, P. Mondalek [27] introduced friction into the Norton-Green compaction model by a viscoplastic approach. Two implementation routes were developed:

i) by a lateral boundary condition on the sample/wall

ii) by an equivalent thin layer at the lateral powder/die interface.

The form of the tangential stress (4) is a function of $c$, a term that depends on the porosity of the material in the Norton-Green model.

$\tau=-\mu K c^{-\frac{m+1}{2}}\left|\boldsymbol{V}_{g}\right|^{m-1} \boldsymbol{V}_{g}$

The tangential stress generated by the boundary layer (5) has a form similar to that of Eq. (4) and depends on the layer thickness $e$.

$\tau=-\frac{1}{e^{m}} K c^{-\frac{m+1}{2}}\left|\boldsymbol{V}_{g}\right|^{m-1} \boldsymbol{V}_{g}$

The friction coefficient is then the inverse of the thickness to the power $m(6)$.

$\mu=\frac{1}{e^{m}}$

It is then possible to vary the layer thickness or the consistency to create an equivalent friction coefficient. The two ways provided comparable results and point out how the powder/die friction influences the relative density gradient. To summarize, the relative density is higher at the points of high relative sliding velocity. On the other hand the relative density is lower at half the height of the pellet, where there is no powder/die sliding due to compaction displacement.

The determination of a powder/solid friction coefficient at high temperature is very difficult and cannot be performed by classical solid/ solid techniques. An interesting method was used by P. Mondalek in her PhD work. The friction coefficient was identified using the observable effect of friction on the relative density field. The simulated and experimental relative density fields obtained by SPS experiments for a TiAl powder are compared for various values of the friction coefficient subsequently introduced into the simulation. Then, the value giving the best simulated/experimental concordance is considered as the friction coefficient. Apart from this study, the modelling of the powder/die friction in the SPS or similar processes is sparse. We can cite the work of J.R. Cho et al. [28] and the work of Ashoka G.K. Jinka et al. [29] on an Abouaf viscoplastic friction model and the work of K.V. Ranjit et al. [26] with the Camclay model.

The aim of the present work is to identify the powder/die friction properties and its effect on the SPS process with various types of contact. The experiments were performed on the SPS machine (Dr. Sinter 2080, SPS Syntex Inc., Japan) of the "Plateforme Nationale CNRS de Frittage Flash" located at University Toulouse III-Paul Sabatier. The SPS column (spacers, punches and mould) is made of graphite (Mersen ref. [23]2333). The geometrical configuration of the punches, mould and powder is reported Fig. 1 with a $20 \mathrm{~mm}$ punch diameter. The powder sintered is a fine-grained alumina of $0.14 \mu \mathrm{m}$ average grain size (alumina 99.99\%, reference TM-DAR, Taimei Chemicals Co. Ltd). To ensure good contact between punches and sample/die and for easy removal of the sample once densified, three types of interfacial materials are generally used: graphite foil (papyex from Mersen), a sprayed layer of graphite or boron nitride powders. Thus, these three powder/die contacts were studied in the present work (Fig. 2). To simulate the densification of the power considered, we used the Olevsky sintering model. Then, the equivalent strain rate $\dot{\varepsilon}_{e q}$ is defined by:

$\dot{\varepsilon}_{e q}=\frac{1}{\sqrt{1-\theta}} \sqrt{\varphi \dot{\gamma}^{2}+\psi \dot{e}^{2}}$

where, $\theta, \dot{e}$ and $\dot{\gamma}$ correspond to the porosity, the shrinkage rate and shape change rates respectively. The latter are given by:

$\dot{e}=\dot{\varepsilon}_{x}+\dot{\varepsilon}_{y}+\dot{\varepsilon}_{z}$

a)

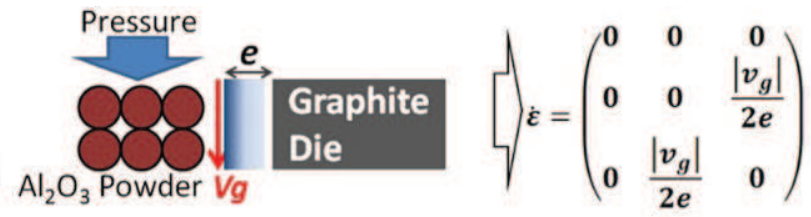

b)

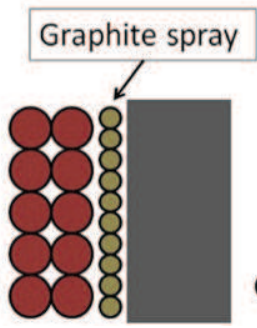

c)
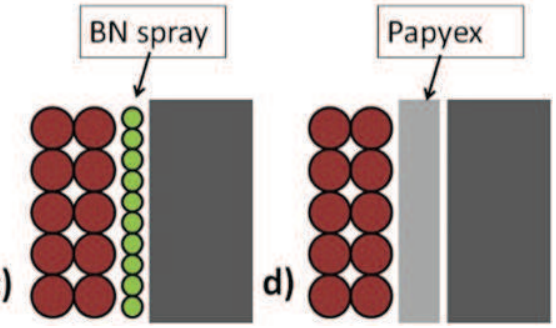

Fig. 2. a) Powder/die interface and the three configurations studied: b) alumina/graphite spray/die c) alumina/boron nitride/die d) alumina/carbon sheet/die. 
$\dot{\gamma}=\sqrt{2\left(\dot{\varepsilon}_{x y}^{2}+\dot{\varepsilon}_{x z}^{2}+\dot{\varepsilon}_{y z}^{2}\right)+\frac{2}{3}\left(\dot{\varepsilon}_{x}^{2}+\dot{\varepsilon}_{y}^{2}+\dot{\varepsilon}_{z}^{2}\right)-\frac{2}{3}\left(\dot{\varepsilon}_{x} \dot{\varepsilon}_{y}+\dot{\varepsilon}_{x} \dot{\varepsilon}_{z}+\dot{\varepsilon}_{y} \dot{\varepsilon}_{z}\right)}$.

The stress tensor $\sigma$ is then defined by the following equation:

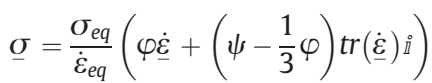

with, $\dot{\varepsilon}$ the strain rate tensor, and $\varphi$ and $\psi$ the shear and bulk moduli respectively:

$\varphi=(1-\theta)^{2}$

$\psi=\frac{2}{3} \frac{(1-\theta)^{3}}{\theta}$

Porosity evolution is linked to the shrinkage rate by the mass conservation equation:

$\frac{\dot{\theta}}{1-\theta}=\dot{\varepsilon}_{x}+\dot{\varepsilon}_{y}+\dot{\varepsilon}_{z}$

Powder/die friction is defined by the hypothesis of a fictive thin boundary layer, the shear strain rate tensor at the interface is then reduced to the form shown in Fig. 2a. Starting from this form, the equivalent strain rate is reduced to:

$\dot{\varepsilon}_{e q}=\frac{\left|\boldsymbol{V}_{g}\right|}{e} \sqrt{\frac{\varphi}{2(1-\theta)}}$.

Introducing Eq. (14) in Eq. (10) and with Eq. (6), we obtain the final expression of the tangential stress on the side wall of the sample.

$\tau=-\mu K \frac{1}{2} \frac{\varphi^{\frac{m+1}{2}}}{(2(1-\theta))^{\frac{m-1}{2}}}\left|\boldsymbol{V}_{g}\right|^{m-1} \boldsymbol{V}_{g}$

For the simulation part, the densification of a cylindrical sample and the interaction with its environment will be considered for the Finite Element Modelling. The lower face of the cylinder has its longitudinal (the cylinder revolution axis direction) displacement fixed, a constant pressure of $100 \mathrm{MPa}$ is applied on the upper face of the cylinder. A temperature ramp up to $1400{ }^{\circ} \mathrm{C}$ with a heating rate $100 \mathrm{~K} \cdot \mathrm{min}^{-1}$ is imposed on the whole cylinder volume. The mould is simulated by a non-penetration condition applied on the wall of the cylinder (that maintain inside the sample mater). The friction boundary condition is also introduced on the sides of the sample using the expression of the tangential stress described previously (15).

In preliminary simulation tests, the friction coefficient is taken in the range of 0.1 to 0.7 . The results of the displacement curves of the upper face of the sample are reported in Fig. 3a and at mid-shrinkage (i.e. $\mathrm{t}=560 \mathrm{~s}$ ) show that increasing the friction coefficient decreases the upper face sample displacement amplitude. The powder/die friction appears to significantly slow down the densification of the powder. This result is expected because the tangential stress due to friction is in the opposite direction of the compaction displacement. The displacement and relative density field reported Fig. $3 \mathrm{~b}$ show the areas affected by the friction. As reported in the literature [26,27] the point of maximum sliding velocity is the point of maximum relative density which here corresponds to the upper corner of the pellet. The greater the friction coefficient, the higher the relative density inhomogeneity and interestingly the higher the curvature of the displacement field. The identification of the friction coefficient by comparison with the relative density field is difficult to set up with fine grain powder, as it is difficult to obtain the experimental density field of the sample in one step. Instead of this approach, we introduced a method of identification of the friction coefficient based on the displacement field curvature of the spark

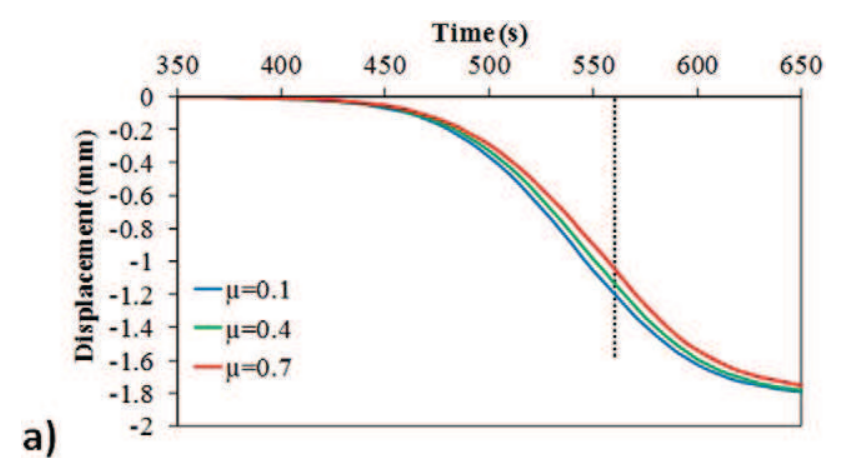

b)

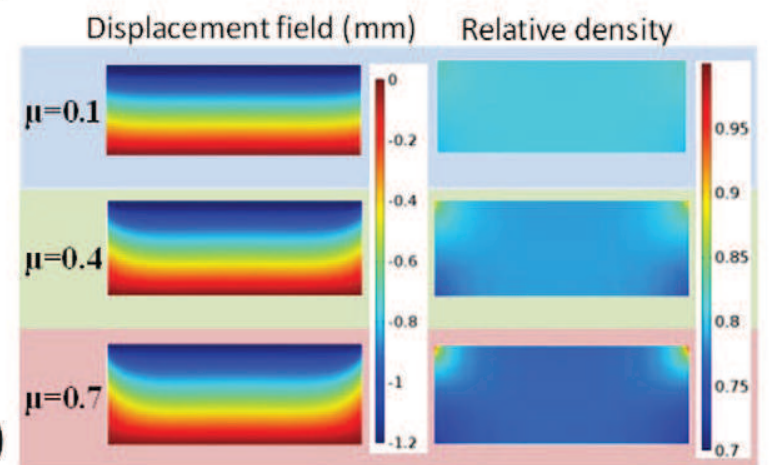

Fig. 3. Simulation of the densification with a powder/die friction coefficient ranging from 0.1 to $0.7: a$ ) the displacement curves of the upper face of the sample b) displacement and density field.

plasma sintered sample. Indeed, increasing the friction coefficient creates a displacement curvature that is more distinguishable compared to the relative density field it generates. In order to reveal the experimental displacement curvature, the alumina powder is introduced into the mould and successively compacted with several horizontal thin sprayed graphite layers placed at different pellet heights. The graphite layers contain a very small quantity of graphite powder, their aim being to illustrate the displacement field by appearing in black lines on a white alumina foreground. In the simulation Fig. 3, the displacement of the lower face of the pellet is fixed. In common sintering configurations the pressure is applied on both side of the pellet creates a shrinkage of the sample and a displacement on both sides. In the experiments, we fixed the lower displacement by two graphite pellets placed between the mould and the spacer. The aim of this configuration is to exaggerate the friction effect on the displacement field and reach higher accuracy in the identification of the friction coefficient. A complete sintering cycle is applied in the same conditions as the simulations Fig. 3. Cross-section images of the pellets and the corresponding simulations of the displacement and relative density fields for the three configurations studied (Papyex, Spray BN and graphite) are reported in Fig. 4. The friction coefficient of the simulations ranges from 0 up to 0.12 . By comparison with the simulated displacement field and the curvature of the graphite black lines observed in the sintered pellets, the experimental images are placed on the friction scale next to the closest simulation. The pellet with the most pronounced curvature (i.e.: the black graphite lines) corresponds to the configuration where graphite spray is deposited at the punch/die interface. From the simulation we can estimate that the friction coefficient is about 0.1 to 0.12 . Concerning the configuration where boron nitrate spray is used, the curvatures of the graphite lines are less pronounced compared to the graphite spray experiment. The curvature field seems to indicate that the friction coefficient is around 0.08. Finally, the experiment with the graphite foil, at the punch/die interface, gives nearly strait graphite lines. If we look carefully at the middle line, it seems to be a little bit curved, this is why we located the images in front of the simulation obtained with a value of 0.02 for the friction coefficient. Anyway, the main explanation 


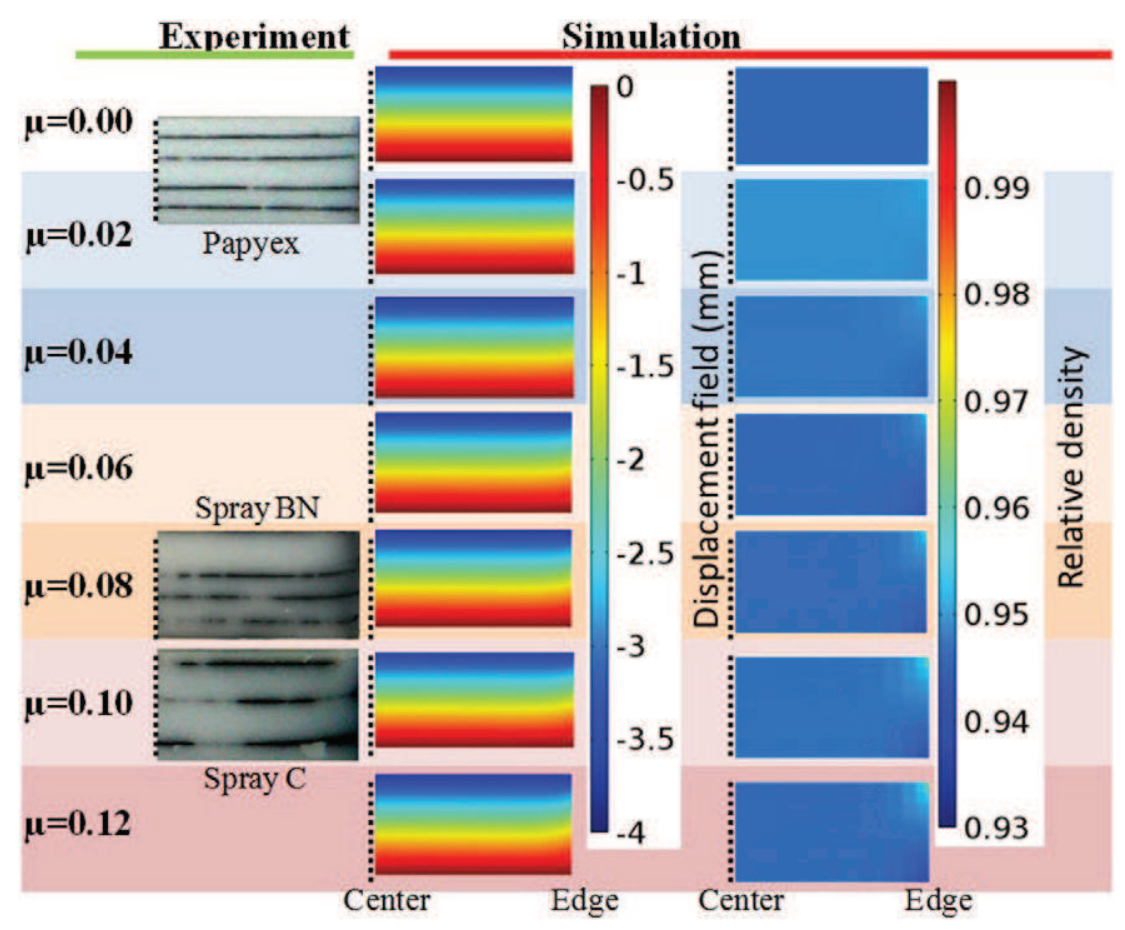

Fig. 4. Identification of the friction coefficient: placement of the experiments next to the corresponding displacement and density field simulated ranging from 0 to 0.12 .

of this low friction coefficient obtained with the use of a graphite foil, compared to those obtained with sprayed powders (BN or graphite) may be found in the nature of the contact. Indeed, with a graphite foil, the contact interface is in fact a double sliding contact. One of these two interfaces is a solid/solid one (papyex/graphite of the die) with very low roughness on both sides of the interface, probably leading to a lower friction coefficient than the other interfaces. Moreover, the graphite foil has the ability to densify during the sintering and follow the displacement of the powder. By opposition, the experiments using sprayed powders give rough interfaces leading to higher friction. Consequently, the solid sheet acts as a better lubricant than the powders. In any event, the friction coefficient is low for all the types of interface and the polished inner die wall is probably the main reason for this. The relative density field corresponding to the experiments involves a difference of $3 \%$ for the graphite and boron nitrate experiments and nearly no differences for the graphite foil contact.

To conclude, in the spark plasma sintering process, the powder/die friction seems to have a noticeable effect on the microstructure of the sample. Depending on the friction intensity the point of maximum sliding displacement is a place of higher localized densification. The powder/die friction coefficient is difficult to identify by classic means, for this reason we developed an identification method based on the displacement curvature generated by the friction. The experimental displacement field is obtained by the use of thin graphite layers in the sample thickness. Three different powder/die contacts were studied, the graphite and boron nitride interfacial powder experiments show a friction coefficient of about 0.1 . The graphite foil experiment shows almost total lack of friction effect. The graphite foil (Papyex) is thus an excellent candidate for minimizing the relative density inhomogeneities caused by powder/die friction.

\section{References}

[1] R. Orrù, R. Licheri, A.M. Locci, A. Cincotti, G. Cao, Mater. Sci. Eng. R 63 (2009) 127-287.

[2] Z.A. Munir, D.V. Quach, M. Ohyanagi, J. Am. Ceram. Soc. 94 (2011) 1-19.
[3] S.H. Risbud, Y.-H. Han, Scr. Mater. 69 (2013) 105-106.

[4] R. Chaim, M. Levin, A. Shlayer, C. Estournès, Adv. Appl. Ceram. 27 (2008) 159-169.

[5] R. Chaim, R. Marder, C. Estournes, Z. Shen, Adv. Appl. Ceram. 111 (5\&6) (2012) 280-285.

[6] S.H. Risbud, C.-H. Shan, A.K. Mukherjee, M.J. Kim, J.S. Bow, R.A. Holl, J. Mater. Res. 10 (1995) 237-239.

[7] R.S. Mishra, S.H. Risbud, A.K. Mukherjee, J. Mater. Res. 13 (1998) 86-89.

[8] A. Zavaliangos, J. Zhang, M. Krammer, J.R. Groza, Mater. Sci. Eng. A 379 (2004) $218-228$.

[9] U. Anselmi-Tamburini, S. Gennari, J.E. Garay, Z.A. Munir, Mater. Sci. Eng. A 394 (2005) 139-148.

[10] K. Vanmeensel, A. Laptev, J. Hennicke, J. Vleugels, O. Van der Biest, Acta Mater. 53 (2005) 4379-4388.

[11] G. Maizza, S. Grasso, Y. Sakka, T. Noda, O. Ohashi, Sci. Technol. Adv. Mater. 8 (2007) 644-654.

[12] S. Grasso, Y. Sakka, G. Maizza, Mater. Trans. 50 (2009) 2111-2114.

[13] C. Maniere, A. Pavia, L. Durand, G. Chevallier, V. Bley, K. Afanga, et al., Electr. Power Syst. Res. 127 (2015) 307-313.

[14] C. Arnaud, C. Manière, G. Chevallier, C. Estournès, R. Mainguy, F. Lecouturier, et al., J. Mater. Sci. 50 (2015) 7364-7373.

15] A. Pavia, Université de Toulouse, PhD Thesis Université Toulouse III Paul Sabatier, 2012.

[16] O. Guillon, J. Gonzalez-Julian, B. Dargatz, T. Kessel, G. Schierning, J. Räthel, et al., Adv . Eng. Mater. 16 (2014) 830-849.

[17] M. Radwan, M. Nygren, K. Flodström, S. Esmaelzadeh, J. Mater. Sci. 46 (2011) 5807-5814.

[18] Z. Shen, M. Johnsson, M. Nygren, J. Eur. Ceram. Soc. 23 (2003) 1061-1068.

[19] K. Matsugi, H. Kuramoto, O. Yanagisawa, M. Kiritani, Mater. Sci. Eng. A 354 (2003) 234-242.

[20] P. Mondalek, L. Silva, M. Bellet, Adv. Eng. Mater. 13 (2011) 587-593.

[21] T. Voisin, L. Durand, N. Karnatak, S. Le Gallet, M. Thomas, Y. Le Berre, et al., J. Mater. Process. Technol. 213 (2013) 269-278.

[22] C. Maniere, L. Durand, G. Chevalier, K. Afanga, C. Estournès, Acta Mater. 102 (2016) 169-175.

[23] M. Abouaf, J.L. Chenot, G. Raisson, P. Bauduin, Int. J. Numer. Methods Eng. 25 (1988) 191-212.

[24] E.A. Olevsky, C. Garcia-Cardona, W.L. Bradbury, C.D. Haines, D.G. Martin, D. Kapoor, J Am. Ceram. Soc. 95 (2012) 2414-2422.

[25] E.A. Olevsky, Mater. Sci. Eng. R 23 (1998) 41-100.

[26] K.V. Ranjit, N.S. Mahesh, M.I. Anwar, SASTech J 11 (2012) 79-84.

[27] P. Mondalek, Paris Tech, PhD thesis Ecole nationale supérieure des mines de Paris, 2012.

[28] J.R. Cho, H.S. Jeong, Int. J. Numer. Methods Eng. 51 (2001) 429-448.

[29] A.G.K. Jinka, M. Bellet, L. Fourment, Int. J. Numer. Methods Eng. 40 (1997) 3955-3978. 